\title{
AN EMPIRICAL STUDY OF CELL PHONE AND SMARTPHONE USAGE
}

\author{
Alan Peslak, Penn State University, arp14@psu.edu \\ Li-Jen Shannon, Sam Houston State University, lys001@shsu.edu \\ Wendy Ceccucci, Quinnipiac University, wendy.ceccucci@quinnipiac.edu
}

\begin{abstract}
In a few short years, a variety of new wireless communication devices have profoundly changed how and why we communicate. Understanding the uses and motivators and characteristics associated with these new forms of communications is important for practitioners and researchers as they increasingly adopt these technologies. This study was to review activities and variables associated with cell phone and smartphone usage among a sample of US college students. The study is an attempt to provide general information on the use of mobile devices today as well as some of the motivators behind use and satisfaction. Specifically, we examine demographic and device differences with regard to a wide range of mobile phone uses as well as influences on satisfaction with mobile devices and uses.
\end{abstract}

Keywords: Wireless communication devices, cell phone usage, smartphone usage, phone activities

\section{INTRODUCTION}

Cell phones have become an integral part of our lives. Just as many adults have a cell phone as have a computer. According to a report by Pew Internet more than $82 \%$ of American adults own a cell phone [15]. A survey done by Ball State of about 300 college students found that 27 percent own a smartphone as compared to the national average of 19 percent for working adults. Two of the main uses of cell phones are voice calling and text messaging. Adults send and receive about 10 texts a day. Today the basic cell phone is being replaced by the smartphone. But what is the difference between a cell phone and smartphone? While there is no industry standard on what defines a smartphone, smartphones have a mobile operating system, which allow users to store information, browse the internet, sync their e-mail, and install programs (often referred to as apps). While text messaging, at 68 percent, is still the most popular smartphone service many of the other services that are more smartphone friendly are growing in use: web browsing (36.4 percent), app usage (34.4 percent), social networking (24.7 percent), listening to music (15.7 percent) and playing games (23.2 percent) [12]. According to Google's recent study on the mobile movement, the smartphone is used as a part of our daily lives by keeping us connected (89\%), for research and read the news (82\%), navigate, (look for directions, maps, 75\%), entertain(65\%) and manage and plan (45\%).

\section{LITERATURE REVIEW}

In this section, the mentioned activities and variables associated with this research will be introduced. First the differing operating systems available for smartphones are briefly discussed. The activities used on smartphones and cell phones such as applications (apps) and games, and phone usages are then presented.

\section{Operating Systems}

The most important software in any smartphone is its operating system. The operating system manages the software and hardware resources of smartphones. The leading operating systems for smartphones are Google's Android, Blackberry's RIM, Apple's iPhone, and Microsoft's Windows Phone 7. According to a study done by comScore [4], the top smartphone platforms are Google (34.7\%), RIM (27.1\%), Apple (25\%), Microsoft (7.5\%), and Palm (2.8\%).

Google's Android. Android is an operating system which provides the open source application for the mobile phone. Android offers a powerful Internet functions which also provides tools via the Internet to let people write their own applications for the phone. The Open Handset Alliance (OHA) is a group of companies that looked at the current generation of mobile phones and decided how to serve the best and give customers a better experience when it 
comes to their mobile phones. These companies range from hardware manufacturers such as HTC, LG Electronics, Motorola, and Samsung, to mobile operators such as T-Mobile and Sprint Nextel, to software companies such as Google and eBay [5]. Anyone with a little time and programming knowledge can produce Android applications. That opens up the mobile phone to a whole new world [10].

Blackberry's RIM. RIM BlackBerry OS is a proprietary platform designed for BlackBerry smartphones produced by Research In Motion Limited (RIM). RIM offers a great combination of mobile phone, server software, push email, and security from a single vendor [13]. RIM makes BlackBerry smartphones through OEM companies. BlackBerry applications are written in Java; therefore, they can run across different cell technologies.

RIM's revenue mainly comes from selling BlackBerry devices and deploying E-mail service solutions [11]. RIM gives IT departments control over which third-party applications they support to make RIM distinguishes between trusted applications and untrusted apps with limited access [13].

Apple's iPhone. The iPhone OS is a proprietary operating system which is a closed smartphone running a closed OS. Apple plays the roles of device maker and vendor, OS owner and service platform maker such as iTunes and App Store. Apple uses its OS to gain control over its product, and it sees iPhone and iPhone OS as a package in the smartphone competition [11]. What stands out is the iPhone's touch-screen design--no thumb-fumbling keyboard [13]. With the iPhone 4, Apple shows that it is a powerful player in the smartphone wars. The newest version of the iPhone, the iPhone4, has a new display, a loaded feature set, and even better performance [7].

Microsoft's Windows Phone 7. Microsoft's business model in smartphone market is a traditional software business which the Windows Mobile model is a purer software business model compared with models of other major OSs. It is Microsoft's ambition to copy its success in the personal computer industry to the smartphone world [11].

Windows Mobile doesn't need extra middleware for wireless e-mail when used with Exchange Server 2003 which leads the PC users find the transition to Windows Mobile smartphones simple [13]. Windows Phone 7 interface. Windows Phone 7 devices have minimum hardware requirements built around robust Qualcomm processors; feature clean and minimalistic, and at least 8 gigabytes of flash memory. Every phone has GPS, an accelerometer, compass, other modern sensors, FM radios, dedicated start, search (leading to Bing) and back buttons [1].

The specific marketing (pricing) strategy and the openness of the operating system have made the different phones appeal to different market segments. More males than females use Android and iPhones. "Android users also tend to be slightly younger than their iPhone peers- 55\% of Android users are under the age of 34 while $47 \%$ of iPhone users fall within the same demographic. Age is also a prime determinant of income and education, with Android users slightly less wealthy and less educated [14]." Regarding to the smartphone operating systems (OS), the OS determines a phone's features, performance, security, and add-on applications and related technology to manage them all [13].

\section{Phone Applications \& Games}

The Horizon Report [9] from the HP Company stated that the recent studies conducted from mobile manufacturer Ericsson showed that by 2015, 80\% of people accessing the Internet will be doing so from mobile devices. This movement might promote the Internet capable mobile devices to outnumber computers within the next year which could indicate the shift in the means of connecting to the Internet is being enabled by the convergence of three trends: the growing number of Internet-capable mobile devices, increasingly flexible web content, and continued development of the networks that support connectivity [9].The smartphones provides the tools to enable comfortable web browsing, reading, watching videos, internet productivity and lifestyle applications. Within a year of the opening of the iTunes App Store, a catalogue of over 65,000 applications has been downloaded. Cochrane and Bateman [3] stated that "smartphones have matured into feature-rich miniature multimedia computers, including features such as HSPA connectivity (3.6 Mb/s and higher wireless mobile broadband connectivity), built in virtual or physical keyboards for easy text entry, a high resolution digital still and video camera, a GPS, high capacity memory storage (now $8 \mathrm{~Gb}$ and higher is standard), high resolution touchscreen user interfaces, and a wide variety of preinstalled and downloadable applications that integrate with Web 2.0 social software (p.2).” 
Developing with the commonly used Android-based phone, the developers are capable of applying many activities for the phones. Ledford, Zimmerly, and Amirthalingam [10] stated that that users can build upon, access, or add to the set of core applications such as (a) connecting with contacts, (b) saving the date in the calendar, (c) figuring with the calculator, (d) using the camera to capture pictures, and (e) capturing and sharing video. With an easy and friendly design, game playing and apps creating became easy tasks for the users.

The evolution of games on mobile devices has gained considerable traction since 2003. Game development $s$ has been recognized for having broad applicability across a wide range of disciplines [9]. Developers and researchers has been working in the area of games that are "goal-oriented; social game environment; non-digital games that are easy to construct and ply; games developed expressly for education; and commercial games that lend themselves to refining team and group skills (p.20).”

\section{Phone Usage}

For the older generation, phone was used as the tool for voice communication. With various applications installed for the mobile phone nowadays, phones quickly become the entertainment and social networking tools. The users are allowed to personalize their own phone besides using the phone as voice and/or text communication. Iftikhar, Gangopadhyay, and Shampur [8] stated that "mobile phone use has already developed a discourse that can be seen and analyzed using different methods and across various media. The choices that individuals make about their mobile phones reflect to themselves (and others) what they enjoy and engage with: the mobile phone is used to construct some aspects of their identity (p. 14)." The phone usage defines the personalization of the object itself which reveals this complex negotiation of self-expression and style. Smartphones have a range of content usage. A report from conScore [4] stated that content usage include: text messaging (68.8\%), used the browser (38.4\%), used downloaded apps (38.6\%), accessed social networking site or blog (26.8\%), played games( $24.6 \%$ ) and listened to music(17.5\%). According to a report by Pew Internet [15], phone usage varies slightly by gender; women make fewer calls than men. However, a report stated by Nielson, found that women overall talk and text more than men. On average, women use 22 percent more cell phone minutes than men, and they even text more, sending 154 more messages per month than the average American man [2]. African American and English-speaking Hispanics are also slightly more likely than white to own a cell phone. Our study specifically focuses on cell phone and smartphone usage of college students. Our research looks at what type of phone students use, how they use it, and the frequency of use.

\section{Motivation for the Study}

As the literature review suggests there have been various studies that have explored mobile phone applications, usage and gender differences. These studies however have been limited and have not statistically analyzed the variables influencing usage. In addition, there is only limited research on the variables affecting satisfaction of mobile phone users and the variety of uses in which they are utilized. Our study starts with an exploration of the uses, both smartphones and non-smartphones, then analyzes variables that influence usage and finally explores satisfaction with mobile phone usage. We see our study's contribution similar to basic science research, which can be used as a starting point for more detailed and applied communication research.

\section{METHODOLOGY}

A survey was prepared and pretested with groups of students at one northeastern U.S. university. The survey was modified based on preliminary testing and administered to 101 students at several US universities. Based on the suggested minimal total sample sizes for different hypothesis tests, a total of 42 samples are needed to provide a medium effect size at the .05 level of significance for the correlation coefficient tests [6]. We collected a valid of 101 samples which met the minimal requirements to conduct further analysis. It is important to note that our age results were fairly limited since we only surveyed college students but there were also a significant number of older students in our sample. Gender was also biased towards males but did include significant numbers of females. The survey was a comprehensive survey of Cell Phone Usage and Behavior. A subset of this study included specific questions that developed into this study. 
Volume XII, No. 1, pp. 407-417, 2011

\section{Research Questions}

The questions explored the following areas: Use of cell phones today including types of phone and operating system, time spent of Internet, texting, and voice. Software used in the study was SPSS 17.0 and AMOS 17. The motivation of the study was to review activities and variables associated with cell phone and smartphone usage. In an attempt to understand these areas three broad research questions were formulated.

RQ1 What types of activities are cell phone and smartphone users engaged in and how do they vary? RQ2 What general variables influence cell phone and smartphone usage? RQ3 What influences satisfaction with cell phone and smartphone usage?

\section{RESULTS}

RQ1 What types of activities are cell phone and smartphone users engaged in and how do they vary?

Please note that the total percentages on tables 1-3 are all over 100 by 4 to 6 percent due to respondent submissions. Overall, it is seen that currently mobile phones have a wide variety of uses today. Tables 1-3 show what percentage of time the respondents spend using the phone for each of the listed activities. The findings showed that much more time is spent on text messaging (51.82\%) than traditional voice messaging (23.88\%) (See Table 1). Internet and email also show substantial usage. It is interesting to note the ranges of percentages that mobile phones are used for various activities. Some use their phones for $100 \%$ voice and others use for $99 \%$ texting. Internet usage is as high as $50 \%$ for some users. All of these findings suggest that mobile devices have become much more than just phones.

Table 1. Descriptive Statistics of All Mobile Phone Usage

\begin{tabular}{lrccr}
\multicolumn{1}{c}{ Items } & N & Minimum & Maximum & Mean \% \\
\hline Voice & 102 & 1 & 100 & 23.88 \\
Text & 101 & 5 & 99 & 51.82 \\
Email & 87 & 0 & 40 & 8.21 \\
Internet & 87 & 0 & 50 & 12.23 \\
Games & 82 & 0 & 30 & 3.09 \\
Other Apps & 82 & 0 & 30 & 4.20 \\
Other Activities & 80 & 0 & 20 & 1.94 \\
\hline
\end{tabular}

When we examine usage by whether the phone is a smartphone or primarily a voice and text phone, we find that regular cell phones are still used more for texting than voice (59.18 to 32.25 percent). Other uses account for 9 percent of usage despite not having smartphone functionality (See Table 2).

Table 2. Descriptive Statistics of Regular Cell Phone Usage

\begin{tabular}{lcccc}
\multicolumn{1}{c}{ Items } & N & Minimum & Maximum & Mean \% \\
\hline Voice & 51 & 1 & 100 & 32.25 \\
Text & 50 & 5 & 99 & 59.18 \\
Email & 37 & 0 & 25 & 3.62 \\
Internet & 38 & 0 & 50 & 5.97 \\
Games & 38 & 0 & 10 & 1.00 \\
Other Apps & 37 & 0 & 5 & 1.08 \\
Other Activities & 37 & 0 & 20 & 1.54 \\
\hline
\end{tabular}


Volume XII, No. 1, pp. 407-417, 2011

Smartphones, however, have a much greater variety in usage. Actually both texting (44.5\%) and Internet usage (17.33\%) are both higher than voice usage (15.32\%) (See Table 3). It could be suggested that phones are no longer phones but rather portable messaging or Internet browser devices. It is also interesting to note that texting remains a very important activity regardless of whether it is a smartphone or not. Smartphone users still have a maximum percentage use of $95 \%$ for texting.

Table 3. Descriptive Statistics of Smartphone Usage

\begin{tabular}{lllll} 
tems & $\mathrm{N}$ & Minimum & Maximum & Mean \% \\
\hline Voice & 50 & 1 & 55 & 15.32 \\
Text & 50 & 10 & 95 & 44.50 \\
Email & 49 & 0 & 40 & 11.43 \\
Internet & 48 & 1 & 50 & 17.33 \\
Games & 44 & 0 & 30 & 4.89 \\
Other Apps & 45 & 0 & 30 & 6.76 \\
Other Activities & 43 & 0 & 10 & 2.28 \\
\hline
\end{tabular}

RQ2 What general variables influence cell phone and smartphone usage?

The survey asked the respondents approximately how much time they spend using their phone. The range of values were from a to 6 which indicated (1) 0-5 minutes, (2) 5-30 minute (3) 30 minutes to an hour (4) 1 - 3 hours, (5) 3-10 hours and (6) more than 10 hours. Research question two explores variables that are associated with time spent on cell phone and smartphone usages. The demographics studied in our survey were gender, age, and whether the phone was considered a smartphone or not. First, we reviewed the approximate usage time on all mobile phone devices (See Table 4). We found that the greatest amount of time was spent on texting followed by voice, Internet and email. On average the sample spent 11 hours per week texting, 4 hours on voice, 2 hours on mobile Internet, and 1 hour on mobile email. These are very large blocks of time and empirically demonstrate the variety and importance of mobile device usage.

Table 4. Approximate Usage Time on All Types of Mobile Phones

\begin{tabular}{|c|c|c|c|c|}
\hline Items & $\mathbf{N}$ & Minimum & Maximum & Mean \\
\hline Voice & 100 & 1 & 6 & 3.29 \\
\hline Text & 101 & 1 & 6 & 4.46 \\
\hline Email & 88 & 1 & 6 & 2.27 \\
\hline Internet & 87 & 1 & 6 & 2.95 \\
\hline Games & 83 & 1 & 5 & 1.72 \\
\hline Other Apps & 87 & 1 & 5 & 1.78 \\
\hline Other & 80 & 1 & 4 & 1.52 \\
\hline
\end{tabular}

Overall time on voice does not vary with age, gender, or whether you have a smartphone or not (See Table 5). Apparently, there are voice requirements that will be met regardless of the type of device. Though decreasing, voice is still important for the users disregarding age, gender, type of phone were not significantly affects the time spent on voice calls. This amount of time was approximately one hour and 40 minutes per week. 
Volume XII, No. 1, pp. 407-417, 2011

Table 5. Regression coefficients of Voice Time

\begin{tabular}{llcc} 
Model & & Unstandardized Coefficients & \\
\hline 1 & (Constant) & B & Sig. \\
\hline & Age & 3.502 & .000 \\
& Gender & .589 & .108 \\
& Smartphone & -.275 & .285 \\
& -.251 & .292 \\
\hline
\end{tabular}

Overall time on texting does not vary by age or smartphone but does by gender. Females text more than the males do significantly ( $<.01$, see Table 6$)$. Overall, average time spent on texting was approximately six and one half hours per week.

Table 6. Regression coefficients of Text Time

\section{Unstandardized Coefficients}

\begin{tabular}{llcc} 
Model & & B & Sig. \\
\hline 1 & (Constant) & 5.654 & .000 \\
& Age & -.156 & .689 \\
& Gender & -.715 & .010 \\
& Smartphone & .137 & .588 \\
\hline
\end{tabular}

Time spent on emailing doesn't vary with age or gender but does with smartphone significantly ( $<<.001$, See Table 7). Time spent on Internet is higher for females at $\mathrm{p}<.001$ and higher for smartphone users at $\mathrm{p}<.01$ (See Table 8). Time on games is higher for males at $\mathrm{p}<.05$ and smartphones. There is no difference based on age (See Table 9). Usage of Apps is only higher for smartphones and is not affected by age or gender (See Table 10).

Table 7. Regression coefficients of Email Time

\begin{tabular}{llll} 
Model & & Unstandardized Coefficients & \\
\hline 1 & (Constant) & B & Sig. \\
\hline & Age & .669 & .438 \\
& Gender & .502 & .254 \\
& Smartphone & -.475 & .132 \\
& 1.207 & .000 \\
\hline
\end{tabular}


Volume XII, No. 1, pp. 407-417, 2011

Table 8. Regression coefficients of Internet Time

\begin{tabular}{llcccrc} 
Model & \multicolumn{7}{c}{$\begin{array}{c}\text { Standardized } \\
\text { Unstandardized Coefficients } \\
\text { Coefficients } \\
\text { B }\end{array}$} & B & Std. Error & Beta & \multicolumn{1}{c}{ t } & Sig. \\
\hline 1 & (Constant) & 1.941 & .869 & & 2.235 & .028 \\
& Age & .042 & .432 & .009 & .098 & .922 \\
& Gender & -.980 & .311 & -.281 & -3.147 & .002 \\
& Smartphone & 1.678 & .293 & .508 & 5.723 & .000 \\
\hline
\end{tabular}

a. Dependent Variable: Please note the approximate time per week that you spend using your phone for each activity - Internet

Table 9. Regression coefficients of Games Time

\begin{tabular}{llccccc} 
Model & & \multicolumn{5}{c}{$\begin{array}{c}\text { Standardized } \\
\text { Unstandardized Coefficients } \\
\text { Coefficients }\end{array}$} \\
\hline 1 & (Constant) & -.371 & .631 & & t & Sig. \\
& Age & -.018 & .311 & -.006 & -.058 & .558 \\
& Gender & .483 & .235 & .214 & 2.061 & .043 \\
& Smartphone & .840 & .214 & .406 & 3.928 & .000 \\
\hline
\end{tabular}

a. Dependent Variable: Please note the approximate time per week that you spend using your phone for each activity - Games

Table 10. Regression coefficients of Other Apps Time

Unstandardized Coefficients

\begin{tabular}{llcc} 
Model & & B & Sig. \\
\hline 1 & (Constant) & -.343 & .590 \\
& Age & .397 & .220 \\
& Gender & .251 & .278 \\
& Smartphone & .836 & .000 \\
\hline
\end{tabular}

$\boldsymbol{R Q 3}$ What influences satisfaction with cell phone and smartphone usage?

Research question three examines effects of demographics and phone type on level of satisfaction with each type of mobile phone activity.

As a starting we examined overall satisfaction level with mobile phones. On a 7 point scale with $1=$ extremely displeased to a 7 = extremely pleased, the overall experience was a 5.69 moving towards very pleased (6). The highest rating was for texting, followed by voice (5, pleased). The Internet, email, and apps were all between pleased and neutral. This suggests these areas can be improved (See Table 11). 
Volume XII, No. 1, pp. 407-417, 2011

Table 11. Overall Satisfaction

\begin{tabular}{lrccc} 
Items & N & Minimum & Maximum & Mean \\
\hline The mobile phone experience overall. & 98 & 4 & 7 & 5.69 \\
The voice quality and signal & 100 & 1 & 7 & 5.06 \\
Texting & 99 & 2 & 7 & 5.81 \\
Email & 89 & 1 & 7 & 4.51 \\
Internet & 88 & 1 & 7 & 4.57 \\
Apps & 90 & 1 & 7 & 4.39 \\
Valid N (listwise) & 87 & & & \\
\hline
\end{tabular}

The next analysis was to examine variables that affected satisfaction levels. It was found that neither gender nor age affected overall satisfaction (See Table 12) but the participants are more satisfied if they have a smartphone at $\mathrm{p}<$ .10 (See Table 13). Presumably the additional applications with smartphones are providing cost effective value added). Females $(\mathrm{p}<.05)$ and smartphone users $(\mathrm{p}<.10)$ are more satisfied with texting (See Table 14). In addition, the participants are more satisfied with voice quality on a smartphone. This may be related to the overall quality of the phone (See Table 13).

Table 12. Variables and Overall Mobile Phone Satisfaction

\begin{tabular}{llcccrc} 
Model & \multicolumn{7}{c}{$\begin{array}{c}\text { Standardized } \\
\text { Unstandardized Coefficients } \\
\text { Coefficients } \\
\text { Beta }\end{array}$} & \multicolumn{1}{c}{ t } & \multicolumn{1}{c}{ Sig. } \\
\hline 1 & (Constant) & 5.046 & .588 & & 8.589 & .000 \\
& Age & .140 & .296 & .049 & .474 & .637 \\
& Gender & .000 & .217 & .000 & -.001 & .999 \\
& Smartphone & .351 & .196 & .186 & 1.791 & .077 \\
\hline
\end{tabular}

a. Dependent Variable: Please rate your satisfaction with the following activities based on a scale of 1 = extremely displeased to a 7 = extremely pleased. - The mobile phone experience overall.

Table 13. Variables and Voice Mobile Phone Satisfaction

\begin{tabular}{llcccrc} 
Model & \multicolumn{7}{c}{ Unstandardized Coefficients } & $\begin{array}{c}\text { Standardized } \\
\text { Coefficients }\end{array}$ \\
\hline 1 & & B & Std. Error & Beta & \multicolumn{1}{c}{ t } & Sig. \\
\hline & Age & 3.683 & .698 & & 5.274 & .000 \\
& Gender & .360 & .365 & .101 & .988 & .326 \\
& Smartphone & .177 & .258 & .070 & .687 & .494 \\
& .473 & .238 & .202 & 1.988 & .050 \\
\hline
\end{tabular}

a. Dependent Variable: Please rate your satisfaction with the following activities based on a scale of 1 = extremely displeased to a 7 = extremely pleased. - The voice quality and signal 
Volume XII, No. 1, pp. 407-417, 2011

Table 14. Variables and Text Mobile Phone Satisfaction

\begin{tabular}{llrrrrr} 
Model & \multicolumn{7}{c}{$\begin{array}{r}\text { Standardized } \\
\text { Coefficients } \\
\text { Unstandardized Coefficients } \\
\text { B STD. ERROR }\end{array}$} & $\begin{array}{r}\text { t } \\
\text { BETA }\end{array}$ \\
\hline 1 & (Constant) & 5.992 & .603 & & 9.942 & .000 \\
& Age & .073 & .314 & .023 & .233 & .817 \\
& Gender & -.489 & .224 & -.219 & -2.180 & .032 \\
& Smartphone & .398 & .206 & .193 & 1.935 & .056 \\
\hline
\end{tabular}

a. Dependent Variable: Please rate your satisfaction with the following activities based on a scale of 1 = extremely displeased to a 7 = extremely pleased. - Texting

Email satisfaction does not vary by gender or age but is clearly more prevalent in smartphones $(\mathrm{p}<.01$, See Table 15).

Table 15. Variables and Email Mobile Phone Satisfaction

\begin{tabular}{llrrrrr} 
& \multicolumn{7}{c}{ Standardized } \\
Model & & Unstandardized Coefficients & Coefficients & t & Sig. \\
\hline 1 & (Constant) & .694 & 1.045 & & .664 & .509 \\
& Age & .612 & .542 & .105 & 1.129 & .262 \\
& Gender & -.069 & .382 & -.017 & -.181 & .857 \\
& Smartphone & 2.109 & .360 & .544 & 5.866 & .000 \\
\hline
\end{tabular}

a. Dependent Variable: Please rate your satisfaction with the following activities based on a scale of 1 = extremely displeased to a 7 = extremely pleased. - Email

Overall Internet satisfaction is the same for gender and age but smartphone users are more satisfied $(\mathrm{p}<.01$, see Table 16).

Table 16. Variables and Internet Mobile Phone Satisfaction

\begin{tabular}{llrrrrr} 
& \multicolumn{7}{c}{$\begin{array}{c}\text { Standardized } \\
\text { Model }\end{array}$} & & Unstandardized Coefficients & Coefficients & t & Sig. \\
\hline 1 & (Constant) & .767 & 1.134 & & .676 & .501 \\
& Age & .589 & .587 & .095 & 1.003 & .319 \\
& Gender & -.131 & .418 & -.030 & -.313 & .755 \\
& Smartphone & 2.193 & .391 & .529 & 5.611 & .000 \\
\hline
\end{tabular}

a. Dependent Variable: Please rate your satisfaction with the following activities based on a scale of 1 = extremely displeased to a 7 = extremely pleased. - Internet

Overall Apps satisfaction is the same for gender and age but smartphone users are more satisfied $(\mathrm{p}<.01$, See Table 17). 
Volume XII, No. 1, pp. 407-417, 2011

Table 17. Variables and Apps Mobile Phone Satisfaction

\begin{tabular}{llrrrrr} 
& \multicolumn{7}{c}{ Standardized } \\
Model & & Unstandardized Coefficients & Coefficients & t & Sig. \\
\hline 1 & (Constant) & -.545 & 1.049 & & -.520 & .605 \\
& Age & .573 & .554 & .094 & 1.035 & .304 \\
& Gender & .511 & .385 & .121 & 1.325 & .189 \\
& Smartphone & 2.247 & .364 & .559 & 6.167 & .000 \\
\hline
\end{tabular}

a. Dependent Variable: Please rate your satisfaction with the following activities based on a scale of $1=$ extremely displeased to a 7 = extremely pleased. - Apps

\section{CONCLUSIONS}

Our study was an attempt at performing basic research on mobile phone usage. The research is primarily focused on providing primary descriptive information and limited inferential statistics on mobile phone usage. Our study is certainly limited by the sample size, the convenience sample, and the age and gender limitations, but we believe our study provides valuable current basic information on mobile phone usage and is valuable to both practitioners and researchers. Future research can validate and expand on the inferential portion of our manuscript.

Our study examined several questions regarding current cell phone and smartphone usage among college students today. These students can be regarded as the vanguard of young adults that are currently forming communication patterns that will be used as they enter the workplace. We see these students as worthy of study. We explored the types of activities cell phone and smartphone users engaged in and how they vary. We found that text messaging is currently the most important means of electronic communications for mobile phone users. For smartphone users, Internet activities are also more important than voice. We explored general variables that influence cell phone and smartphone usage and found the age and gender or type of mobile device does not affect amount of time on voice calls but gender does impact text messaging usage. A variety of other activities are also affected by type of mobile device. Finally, we explored what influences satisfaction with cell phone and smartphone usage and found that in general females and smartphone users are more satisfied with texting. Overall satisfaction is also significantly higher for smartphone users. Researchers and practitioners can use these findings to improve marketing efforts and improve communications across the world.

\section{REFERENCES}

1. Baig, E. C. (2011). Review: Microsoft Windows Phone 7 has its pluses, but ... USA TODAY. Retrieved May 13, 2011, from http://www.usatoday.com/tech/columnist/edwardbaig/2010-11-03-baig03_CV_N.htm

2. Blackburn, Bradley (2010), Nielsen Company Data Outlines Cell Phone Usage Across the United States, ABC World News, Retrieved May 13, 2011, from http://abcnews.go.com/WN/cell-phones-demography-nielsen-databreaks-mobile-phone/story?id=11468925

3. Cochrane, T. \& Bateman, R. (2010). Smartphones give you wings: Pedagogical affordances of mobile Web 2.0. Australasian Jounral of Educational Technology. 26(1). 1-14.

4. comScore Reports. (March, 2011). U.S. Mobile Subscriber Market Share. Retrieved May 13, 2011, from http://www.mobilemarketingwatch.com/comscore-report-shows-surge-in-android-smartphone-os-usage-15167/

5. Eddy, J., \& Eddy, P.D. (2009). Google on the go: Using and android-powered mobile phone. Indianapolis: Indiana. Que.

6. Gall, M, Gall, J.P., \& Borg, W.R. (2003). Educational Research An introduction (7 $7^{\text {th }}$ ed.). Boston: Pearson Education.

7. German, K. (2011). Apple iPhone 4 - 32GB - black (AT\&T). Retrieved May 13, 2011, from http://reviews.cnet.com/iphone-4-review.

8. Iftikhar, U.S., Gangopadhyay, A., \& Shampur, N.V. (2010) Web-based geospatical services: Implementing interoperability speculations. in Lloyd, Cl. \& Gillard, P. (2010). Discursive practices and creation of identity 
Volume XII, No. 1, pp. 407-417, 2011

using the mobile phone. In Taiwo, R. (Ed.) Handbook of research on discourse behavior and digital communication: language structures and social interaction. Hershey: Pennsylvania. IGI Global.

9. HP. (2011). The Horizon Report. CA: Stanford: The New Media Consortium.

10. Ledford, J., Zimmerly, B., \& Amirthalingam, P. (2009). Web geek's guide to the Android-enabled phone. Indianapolis: Indiana. Que.

11. Lin, F., \& Ye, W. (2009). Operating system battle in the ecosystem of smartphone industry. Information Engineering and Electronic Commerce, 2009 International Symposium on Information Engineering and Electronic Commerce. 617-621.

12. Lunden, Ingrid (2011) Smartphone usage up 60\%; Android makes biggest gains. mocoNews.net unhealthily Obsessed with Mobile Content. http://moconews.net/article/419-smartphone-usage-up-60-percent-androidmakes-biggest-gains/

13. Malykhina, E. (2007). Analysis: How smartphone platforms compare. InformationWeek, Retrieved May 13, 2011, from http://www.informationweek.com/news/personal tech/showArticle.jhtml?articleID=196902226

14. Nielson Company (2010), Android, iPhone OS Market Share Grow 2\%. Retrieved May 13, 2011, from http://www.marketingvox.com/android-iphone-os-market-share-grow-2-047091/

15. Pew Internet. (2010). Cell phones and American adults, Pew Research Center. Retrieved May 13, 2011, from http://pewinternet.org/Reports/2010/Cell-Phones-and-American-Adults.aspx 